\title{
Variaciones nucleotídicas de dos grupos de tepezcuintles, Agouti paca (Rodentia: Agoutidae), en cautiverio provenientes de dos localidades de Yucatán, México
}

\author{
Rubén C. Montes-Pérez ${ }^{1}$, Adán W. Echeverría García ${ }^{1}$, Jorge Zavala Castro² \& Militza G. Alfaro \\ Gamboa $^{1}$ \\ 1 Facultad de Medicina Veterinaria y Zootecnia, Universidad Autónoma de Yucatán. Apdo. 4-116. Itzimná. CP. 97100. \\ Mérida, Yucatán, México. Fax: (99) 423205; mperez@tunku.uady.mx \\ 2 Centro de Investigaciones Regionales “Dr. Hideyo Noguchi”. Av. Itzaes y Calle 59. Centro. CP. 97000. Mérida, \\ Yucatán, México.
}

Recibido 22-VII-2001. C Corregido 26-X-2003. Aceptado 18-VII-2004.

\begin{abstract}
Nucleotidic variations of two captive groups of tepezcuintle, Agouti paca (Rodentia: Agoutidae), from two sites in Yucatan, Mexico. The objective of this work was to estimate the nucleotidic variation between two groups of tepezcuintles (Agouti paca) from the states of Campeche and Quintana Roo, Mexico and within members of each group. Blood samples were collected from eleven A. paca kept in captivity. DNA from leukocytic cells was used for Ramdom Amplification of DNA Polimorphism (RAPD). The primers three 5'd(GTAGACCCGT)- 3' and six 5'-d(CCCGTCAGCA)- 3' were selected from de Amersham kit (Ready.To.Go. RAPD Analysis Beads, Amersham Pharmacia Biotech), because they produced an adequate number of bands. The electrophoretic pattern of bands obtained was analyzed using software for phylogenetic analysis based on the UPGMA method, to estimate the units of nucleotidic variation. The phylogenetic tree obtained with primer three reveals a dicotomic grouping between the animals from both states in the Yucatan Peninsula showing a divergent value of 1.983 nucleotides per hundred. Animals from Quintana Roo show a grouping with primer six; an additional grouping was observed with animals from Campeche. Nucleotidic variation between both groups was 2.118 nucleotides per hundred. The nucleotidic variation for the two primers within the groups from both states, showed fluctuating values from 0.46 to 1.68 nucleotides per hundred, which indicates that nucleotidic variation between the two groups of animals is around two nucleotides per hundred and, within the groups, less than 1.7 nucleotides per hundred. Rev. Biol. Trop. 54 (3): 911-917. Epub 2006 Sept. 29.
\end{abstract}

Key words: tepezcuintle, Agouti paca, RAPD, nucleotidical variation, phylogenetic tree, nucleotides.

En diferentes especies se han efectuado análisis de ADN por medio de la amplificación aleatoria de fragmentos polimórficos de ADN, denominado en inglés RAPD; con el fin de conocer las variaciones nucleotídicas para estimar las relaciones filogenéticas entre diferentes taxa (Bailey y Lear 1994, Chelomina et al. 1999). Esto ha conducido a proponer tendencias evolutivas, como por ejemplo en la rana leopardo (Kimberling et al. 1996). Asimismo estos análisis permiten detectar polimorfismos dentro de una misma especie.
Tales polimorfismos permiten identificar marcadores genéticos que facilitan el seguimiento de líneas, razas y de parentesco, como ha sido informado para una especie de camarones tigre negro de Tailandia donde la utilización de marcadores RAPD permitió detectar el grado de relación genética en núcleos reproductores (Tassanakajon et al. 1997).

Esta técnica es importante cuando se aplica a colonias de animales domésticos y no domésticos en los que no existen registros genealógicos, pues faculta estimar el grado de parentesco 
entre individuos (Ellsworth et al. 1993). En el estado de Yucatán México, generalmente las Unidades de reproducción de animales no domésticos, como por ejemplo de venado cola blanca (Odocoileus virginianus) no cuentan con dichos registros (González 2002), incluso el $76 \%$ de estos cautiverios cuentan con pocos ejemplares, entre uno y 20 (May 1995). En éstos la reproducción se efectúa de manera no controlada, lo cual trae por consecuencia la posibilidad del cruzamiento entre animales estrechamente emparentados. Dicha situación conduce a erosionar la variabilidad genética y por lo tanto a que estas Unidades de crianza presenten en un futuro elevados índices de endogamia en el núcleo reproductor (Da Silva y Gerrits 1994). En el tepezcuintle (Agouti paca), no existe información que registre alguna técnica que pudiera ser aplicada para estimar el grado de variabilidad genética de colonias de animales mantenidos en cautiverio, condición que permitiría detectar animales con mayor o menor variación genética.

Con base en este contexto, el objetivo del presente trabajo fue estimar las variaciones nucleotídicas entre y dentro de dos grupos de tepezcuintles en cautiverio procedentes de los estados de Campeche y Quintana Roo, México.

\section{MATERIALES Y MÉTODOS}

Animales y condiciones: Se utilizaron once tepezcuintles (A. paca) identificados con número, los cuales están confinados en la Unidad de Manejo de Vida Silvestre denominado Xmatkuil ubicado en el estado de Yucatán,

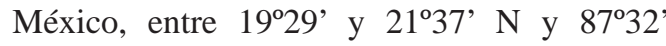
y $90^{\circ} 25^{\prime}$ W. Dicha localidad presenta clima tropical subhúmedo, clasificación Awo según García (1988).

Cuatro animales procedían del estado de Campeche, seis de Quintana Roo y uno nacido en la Unidad pero cuyos padres procedían del estado de Quintana Roo. Ambos sitios localizados en la zona occidente y oriente respectivamente, en la Península de Yucatán, México.
Obtención de linfocitos: Se colectaron $3 \mathrm{ml}$ de sangre de los once tepezcuintles mediante punción cardíaca; las muestras fueron centrifugadas inmediatamente para separar el paquete celular. La muestra sanguinea se mezcló con 500 microlitros ( $\mu \mathrm{l})$ de ácido acético al $3 \%$ y por centrifugación se pudo obtener únicamente los leucocitos.

Aislamiento de ADN: Posteriormente se aisló el ADN contenido en los leucocitos, mediante un estuche comercial (DNA/RNA Isolation kit, Amersham); brevemente se mencionan los componentes de la técnica utilizada: a) ruptura de leucocitos, b) digestión de proteínas, c) eliminación de ARN, d) extracción de proteínas y e) precipitación de ADN.

Se probaron diferentes concentraciones de ADN de las muestras para encontrar la concentración adecuada para practicar la técnica RAPD, la concentración adecuada de las muestras fue de $50 \mathrm{ng} / \mu \mathrm{l}$.

RAPD: La técnica utilizada corresponde al estuche comercial XY-065-00-10 (Ready. To.Go RAPD Analysis Beads, Amersham Pharmacia Biotech). De los seis iniciadores del estuche, se escogieron los números tres y seis, ambos de diez pares de bases, de acuerdo al número de polimorfismos presentes y que permitían hacer una mejor comparación. Los principales pasos que constituyen la técnica son: (a) Mezcla de las perlas de RAPD con cada uno de los iniciadores escogidos del estuche comercial, el ADN extraído de las muestras y agua destilada estéril. (b) Colocación de la mezcla en el termociclador y ejecución del protocolo de amplificación: un ciclo de $5 \mathrm{~min}$ a $95^{\circ} \mathrm{C}$, para la desnaturalización inicial del $\mathrm{ADN} ; 45$ ciclos a $94{ }^{\circ} \mathrm{C}$ por $1 \mathrm{~min}, 36{ }^{\circ} \mathrm{C}$ por $1 \mathrm{~min}, 72{ }^{\circ} \mathrm{C}$ por $2 \mathrm{~min} \mathrm{y}$, un tiempo de elongación final de 7 min a $72{ }^{\circ} \mathrm{C}$.

Análisis de datos: Una vez amplificadas las muestras con cada uno de los iniciadores seleccionados, los productos de la amplificación se corrieron por electroforesis en geles 
de agarosa al $2 \%$. Los geles se tiñeron con Bromuro de etidio y el patrón de bandas fue observado mediante un transiluminador de rayos UV. Se tomaron fotografías a cada gel, que fueron digitalizadas en un scanner para trabajarlas en un programa de diseño fotográfico en un ordenador, se midió en centímetros el desplazamiento que presentaron cada una de las bandas polimórficas para cada muestra. Las distancias recorridas por las bandas en cada uno de los geles fueron procesadas por el Método de Agrupamiento en Pares No Ponderados con Media Aritmética (UPGMA por sus siglas en inglés) con la ayuda de un programa para Análisis Filogenético (Poot-Ferrera y Zavala-Castro 1995).

El resultado del tratamiento de datos produjo dos dendrogramas, uno para cada iniciador, que agrupan a los animales de acuerdo a la variación nucleotídica presente entre las muestras. Es necesario señalar que mientras más alto es el valor de variabilidad la relación genética es menor.

\section{RESULTADOS}

El patrón de bandas obtenidos con el RAPD utilizando el iniciador tres, se muestra en la Fig. 1A, B . Se obtuvo un promedio de ocho bandas por animal. El patrón de bandas obtenidas con el iniciador seis se muestra en la Fig. 2A, B. Se encontró un promedio de 12.7 bandas por animal. En ambos iniciadores el tamaño de las bandas fue menor a $2.0 \mathrm{~kb}$.

La Fig. 3 muestra el dendrograma que relaciona por grupos a los once animales cuando se utilizó el iniciador tres. Se observan dos agrupaciones principales, una con los animales de Quintana Roo, con una variación entre grupo que oscila entre 0.698 y 1.474 nucleótidos de cada cien, y otra formada por el grupo procedente de Campeche cuyo valor más bajo es 0.882 nucleótidos de cada cien y el más alto de 1.632 nucleótidos de cada cien. Ambos grupos (Campeche y Quintana Roo) se encuentran unidos en 1.983 esto es, varían en casi dos nucleótidos de cada 100.

La Fig. 4 exhibe el dendrograma de los mismos animales, cuando se utilizó el iniciador seis. Muestra también dos agrupaciones de animales, una procedente de Quintana Roo con un valor de variación nucleotídica dentro del grupo que se encuentra entre 0.463 y 1.219 nucleótidos de cada cien, y otra agrupación con animales de Campeche y Quintana Roo, con un valor de variación nucleotídica dentro del grupo que va de un valor menor de 0.616 nucleótidos de cada cien hasta el valor más alto de 1.687 nucleótidos de cada cien. Estos dos grupos se encuentran unidos en el dendrograma, señalando una variación de 2.118 nucleótidos de cada 100.

Con ambos iniciadores, en los dos dendrogramas, se encontró que el valor mas bajo de variación corresponde al que presenta el grupo

A

$\begin{array}{lllllllllll}08 & 017 & 05 & 06 & 18 & 012 & 016 & 013 & 04 & 014 & 001\end{array}$

B
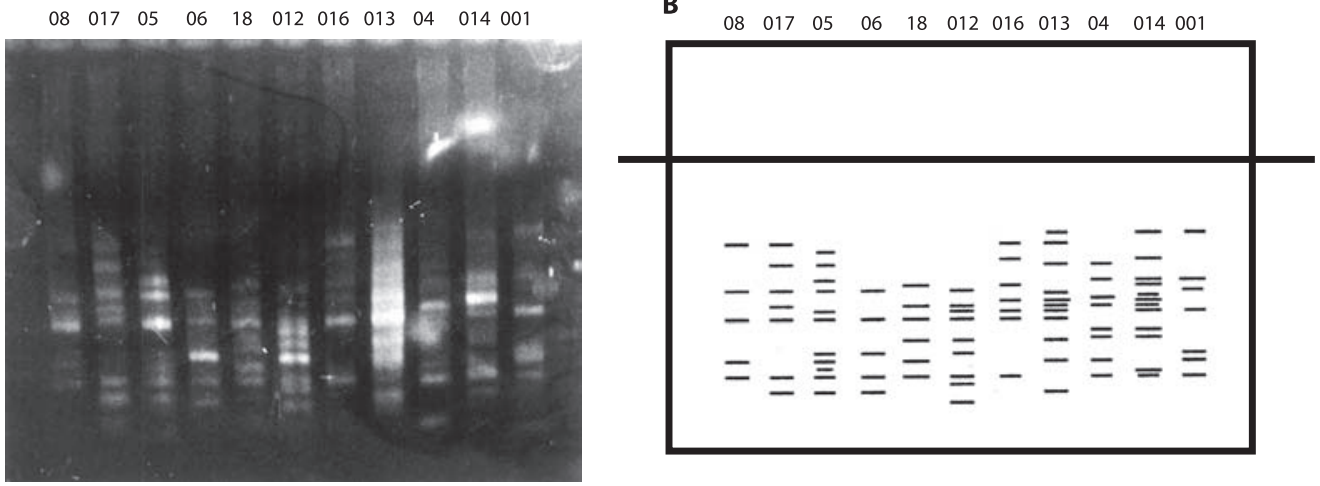

Fig. 1. A-B. Fotografía y esquema del patrón de bandas obtenido utilizando el iniciador 3.

Fig. 1. A-B. Photograph and scheme of band pattern obtained with primer 3. 
A

$\begin{array}{lllllllllll}08 & 017 & 05 & 06 & 18 & 012 & 016 & 013 & 04 & 014 & 001\end{array}$

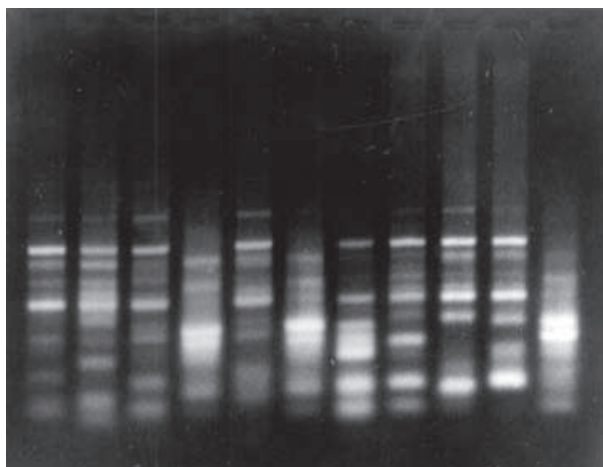

B

$\begin{array}{lllllllllll}08 & 017 & 05 & 06 & 18 & 012 & 016 & 013 & 04 & 014 & 001\end{array}$

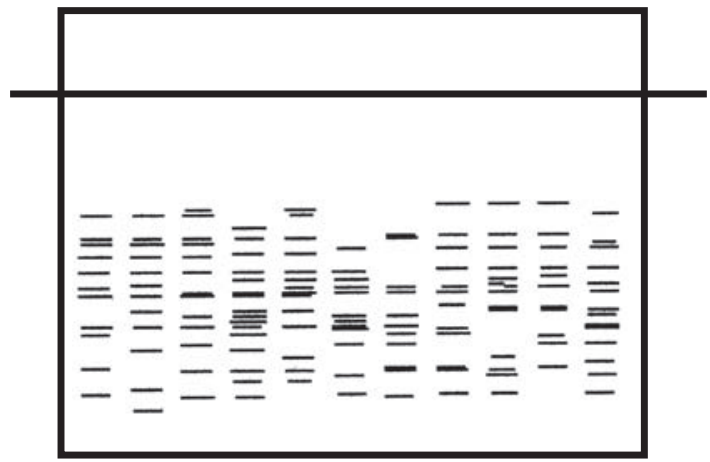

Fig. 2. A-B. Fotografía y esquema del patrón de bandas obtenido utilizando el iniciador 6.

Fig. 2. A-B. Photograph and scheme of band pattern obtained with primer 6.

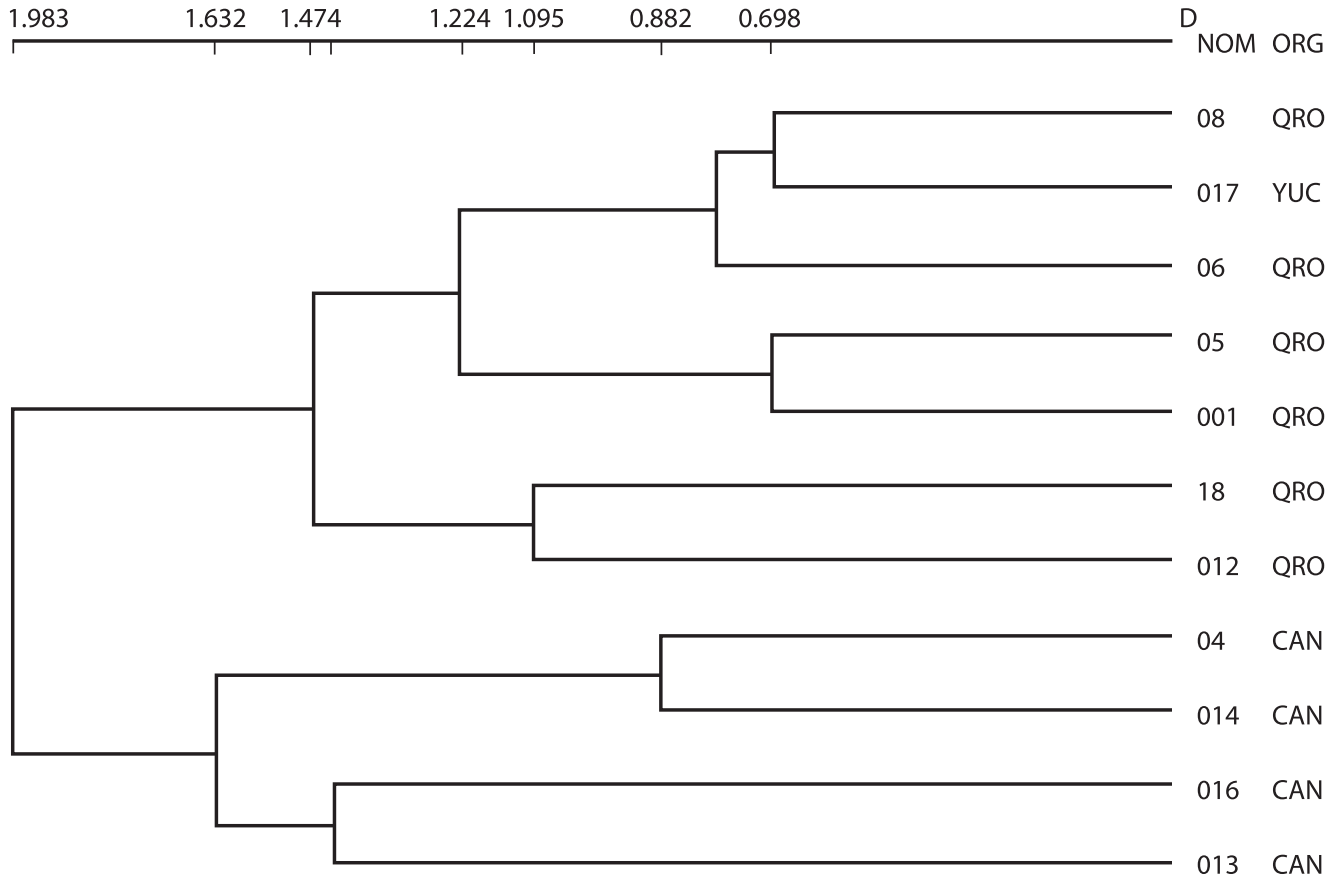

Fig. 3. Dendrograma del iniciador 3, cuya secuencia nucleotídica es 5' -d(GTAGACCCGT)-3’. Se indica la procedencia de la muestra (lado derecho), y el índice de variaciones nucleotídicas (parte superior).

Fig. 3. Phylogenetic tree from primer 3 with a nucleotidic sequence of 5' -d(GTAGACCCGT)-3'. Origin of sample (right side), nucleotidic variation index (at the top).

formado por las muestras 08 y 017 , que son madre e hija respectivamente, cuyos valores son 0.698 nucleótidos de cada cien para el iniciador tres y 0.463 nucleótidos de cada cien para el iniciador seis.

\section{DISCUSIÓN}

El número total de bandas para el iniciador seis fue mayor que para el iniciador tres; sin embargo, el dendrograma del iniciador tres 


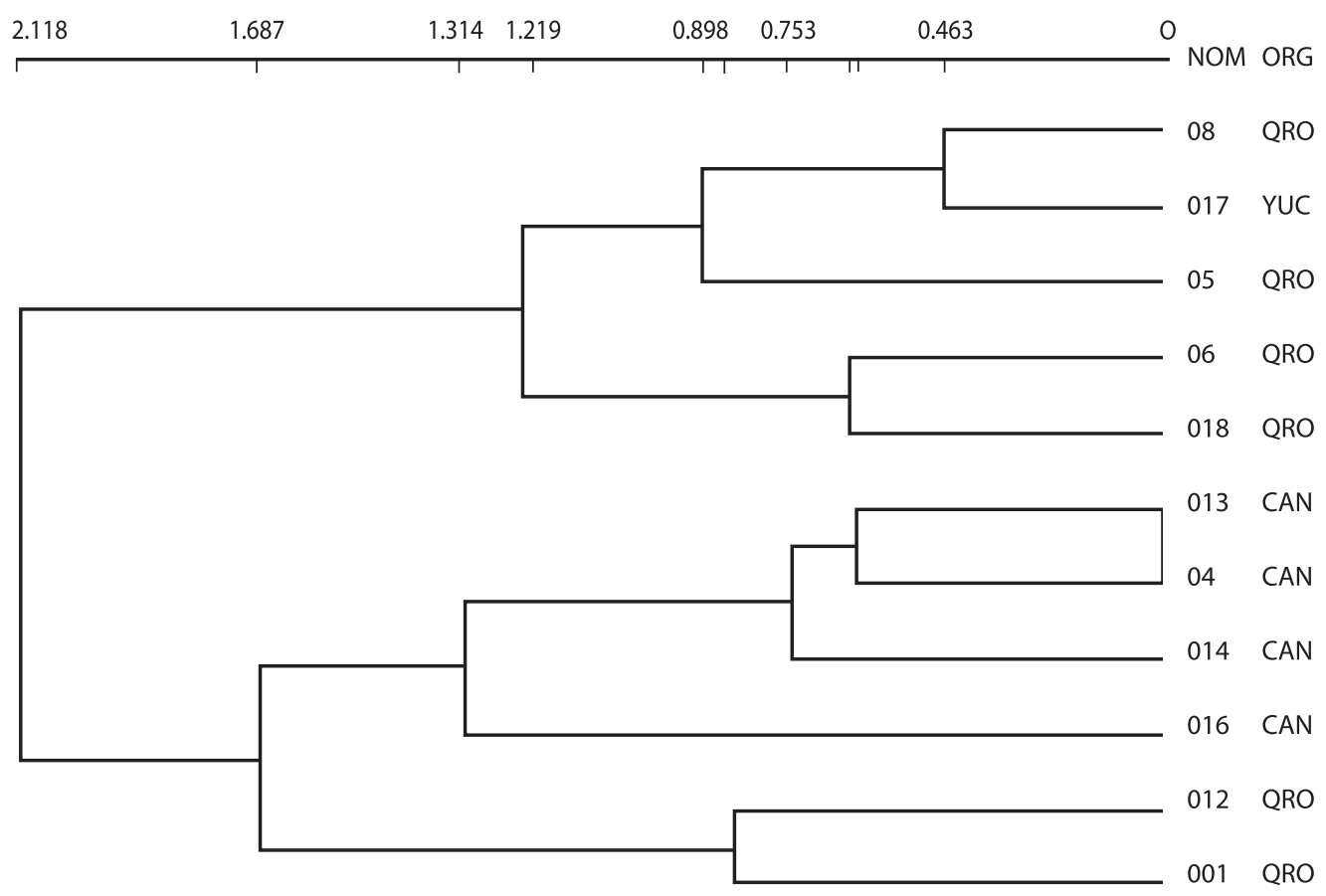

Fig. 4. Dendrograma del iniciador 6, cuya secuencia nucleotídica es 5’ -d(CCCGTCAGCA)-3’.

Fig. 4. Phylogenetic tree form primer 6 with a nucleotidic sequence of 5' -d(CCCGTCAGCA)-3'.

registró un agrupamiento más definido de la procedencia de las muestras. El tamaño de las bandas obtenidas en este estudio con ambos iniciadores, concuerdan con los trabajos realizados por Tassanakajón et al. (1997) quienes obtuvieron bandas en un rango entre 200 y 2000 pb para camarones tigre negro (Penaeus monodon), con iniciadores del mismo tamaño.

Los valores de variación nucleotídica entre los grupos de animales procedentes de Campeche y Quintana Roo, obtenidos con los iniciadores tres y seis son similares, ambos con variaciones alrededor de dos nucleótidos por cada 100. Con los dos iniciadores la variación fue mayor entre los grupos de Campeche y Quintana Roo, que entre los individuos pertenecientes al mismo agrupamiento de procedencia, estos resultados concuerdan con los estudios en Rana pipiens por Kimberling et al. (1996), quienes señalan mayor diferencia entre grupos que dentro de éstos, cuando proceden de diferentes localidades.
También se encontró en el presente estudio que la menor variación nucleotídica se presentó en los grupos formados por madre (08) y cría (017), para ambos iniciadores, esto permite considerar la posibilidad de aplicar la técnica de RAPD para la selección de animales en un programa de cruzamiento, tal como lo señalan Ellsworth et al. (1993); en virtud de que los polimorfismos se transmiten por herencia Mendeliana y por ello la técnica de RAPD es una técnica útil para la planeación de esquemas de cruzamientos a través de marcadores genéticos, principalmente cuando no existen registros genealógicos de los animales criados en cautiverio.

Asimismo, con base en los resultados obtenidos en este estudio, se puede sugerir que la secuencia nucleotídica que presenta el iniciador tres (5'-d(GTAGACCCGT)-3'), podría ser utilizado como marcador genético para poblaciones de esta especie en esta región. De la misma forma Tassanakajón et al. (1997) en 
estudios realizados con camarones tigre negro en Tailandia, designaron la secuencia de un iniciador como marcador para poblaciones específicas de una localidad.

Cabe mencionar, que si bien nuestros resultados sientan las bases para encontrar marcadores genéticos en $A$. paca, el conocimiento sobre la heredabilidad de los rasgos es aparentemente nulo para la especie y, en virtud del pequeño tamaño de la muestra utilizada, hace necesario validar la utilidad de estas dos secuencias nucleotídicas como marcadores genéticos para cualquier población de $A$. paca.

Por otro lado no existe estudio previo que permita señalar si el valor obtenido de variación, de dos nucleótidos por cada cien entre un grupo proveniente de una localidad y de otra, es alto o bajo para esta especie. Sin embargo, en el estudio realizado por el equipo de Tassanakajón et al. (1998), también emplearon el método de UPGMA, y encontraron valores de variación genética entre poblaciones reconocidas geográficamente de 14.976 y de $2.632 \%$ dentro de una misma población; los valores encontrados en nuestro estudio son menores pero cercanos a lo informado por esos autores.

Se concluye en este trabajo que, en una colonia de tepezcuintles en cautiverio, provenientes de dos zonas geográficamente diferentes (Campeche y Quintana Roo) se presentó una variación nucleotídica entre grupos (2 nucleótidos por cada cien) mayor que la estimada dentro de cada grupo de procedencia (menos de 1.7 nucleótidos de cada cien). Esta información sirve de base para hacer comparaciones de las divergencias genéticas de poblaciones de tepezcuintle criados en cautiverio o capturados en condiciones silvestres.

\section{RESUMEN}

Estimamos las variaciones nucleotídicas entre dos grupos de tepezcuintles (Agouti paca) provenientes de los estados de Campeche y Quintana Roo, México y, dentro de cada grupo. Se colectaron muestras sanguíneas de once A. paca mantenidos en cautiverio. El ADN de leucocitos se utilizó para efectuar la amplificación aleatoria de polimorfismos de ADN (RAPD). Se seleccionaron los iniciadores número tres 5' -d(GTAGACCCGT)-3’ y seis 5' -d(CCCGTCAGCA)-3' del estuche (Ready.To.Go. RAPD Analysis Beads, Amersham Pharmacia Biotech), porque produjeron un adecuado número de bandas. Los patrones electroforéticos de bandas fueron procesados con el software para análisis filogenético basado en el método de UPGMA para estimar la variación nucleotídica. El árbol filogenético obtenido con el iniciador tres reveló una agrupación dicotómica entre los animales de ambos estados de la Península de Yucatán, con un valor de divergencia de 1.983 nucleótidos de cada cien. Los animales de Quintana Roo mostraron un agrupamiento con el iniciador seis y, otro grupo más con animales procedentes de Campeche. La variación nucleotídica entre estos dos grupos fue de 2.118 nucleótidos por cada cien. Las variaciones nucleotídicas dentro de los grupos procedentes de ambos estados, para los dos iniciadores, mostraron valores que fluctuaron entre 0.46 y 1.68 nucleótidos de cada cien, lo cual indica que la variación nucleotídica entre los dos grupos de animales es alrededor de dos nucleótidos por cada cien y, dentro de grupos es menor a 1.7 nucleótidos por cada cien.

Palabras clave: tepezcuintle, Agouti paca, RAPD, variación nucleotídica, árbol filogenético, nucleótidos.

\section{REFERENCIAS}

Bailey, E. \& T.L. Lear. 1994. Comparision of Thoroughbred and Arabian horses using RAPD markers. Anim. Genet. 25: 105-108.

Chelomina, G.N., L.N. Spiridonova, M.M. Kozyrenko, E.V. Artiukova, Iu.V. Chelomin \& Iu.N. Zhuravlev. 1999. Use of RAPD-PCR analysis of cellular DNA for the evaluation of genetic plymorphism and subspecies diagnostics of the Far Eastern leopard Panthera pardus orientalis. Genetika 35: 681-687.

Da Silva, A. \& R. Gerrits. 1994. Current development in the conservation of domestic animal diversity: The Americas. Vol. 21, p. 447-454. In C. Smith, J.S. Gavora, B. Benkel, J. Chesnais, W. Fairfull, J.P. Gibson, B.W. Kennedy \& E.B Burnside (eds.). Proceedings of the $5^{\text {th }}$ World Congress on Genetics Applied to Livestock Production. University of Guelph, Ontario, Canadá.

Downie, M.N. \& R.W. Heath. 1986. Métodos estadísticos aplicados. Harla, México D.F., México.

Ellsworth, D.L., K.D.V. Rittenhouse \& R.L. Honeycutt. 1993. Artifactual variation in randomly polymorphic DNA banding patterns. Biotechniques 14: 214-217.

García, E. 1988. Modificaciones al sistema de clasificación climática de Köppen para adaptarlos a las condiciones de la República Mexicana. Instituto de Geografía, Universidad Nacional Autónoma de México, México. 
González, M.R.M. 2002. Diagnóstico de situación de las Unidades para la Conservación, Manejo y Aprovechamiento Sustentable de Fauna Silvestre (UMAs), en el estado de Yucatán, México. Universidad Autónoma de Yucatán, Mérida, Yucatán, México.

Kimberling, D.N., A.R. Ferreira, S.M. Shuster \& P. Keim. 1996. RAPD marker estimation of genetic structure among isolated northern leopard frog populations in the south-western USA. Mol. Ecol. 5: 521-529.

May, A. 1995. Caracterización del Aprovechamiento y Explotación de los Venados. Visión Global y Estudios de Casos en el Estado de Yucatán. Instituto Agropecuario No. 2. Conkal, Yucatán, México.
Poot-Ferrera, M.J. \& J.E. Zavala-Castro. 1995. Desarrollo de un Programa de Computación para Análisis Filogenético a través de Fragmentos de Restricción. Rev. Biomed. 6: 76-82.

Tassanakajon, A., S. Pongsomboon, V. Rimphanitchayakit, P. Jarayabhand \& V. Boonsaeng. 1997. Random amplified polymorphic DNA (RAPD) markers for determination of genetic variation in wild population of the black tiger prawn (Penaeus monodon) in Thailand. Mol. Mar. Biol. Biotechnol. 6: 110-115.

Tassanakajon, A., S. Pongsomboon, P. Jarayabhand, S. Klinbunga \& V. Boonsaeng. 1998. Genetic structure in wild populations of black tiger shrimp (Penaeus monodon) using randomly amplified polymorphic DNA analysis. J. Mar. Biotechnol. 6: 249-254. 
